\title{
ANIMAL AND PUBLIC HEALTH SIGNIFICANCE OF CHLAMYDIOSIS
}

Ishtiaq Ahmed ${ }^{1 *}$, Sarmad Ali ${ }^{1}$, Muhammad Shahid ${ }^{2}$, Aziz ur Rehman ${ }^{1}$, Muhammad Imran Arshad ${ }^{3}$, Muhammad Arfan Zaman $^{4}$ and Muhammad Kashif Saleemi ${ }^{5}$

${ }^{1}$ Department of Pathobiology, College of Veterinary \& Animal Sciences, Jhang (Sub-campus of UVAS, Lahore)

${ }^{2}$ Center of Microbiology and Biotechnology, Veterinary Research Institute, Peshawar

${ }^{3}$ Institute of Microbiology, University of Agriculture, Faisalabad

${ }^{4}$ Department of Pathobiology, College of Veterinary \& Animal Sciences, Jhang (Sub-campus of UVAS, Lahore)

${ }^{5}$ Department of Pathology, Faculty of Veterinary Science, University of Agriculture, Faisalabad

*Corresponding author: ishtiaqahmed@uvas.edu.pk

\section{INTRODUCTION}

Chlamydiaceae family has only one genus known as Chlamydia, which has eleven member species. Amongst those, Chlamydia abortus (C. abortus) occupies an important place due to its ability to induce abortion in sheep and goats and the risk of zoonosis (Sachse et al. 2015). The disease in sheep is known as Ovine Chlamydiosis, Ovine Enzootic Abortion (OEA) or Enzootic Abortion of Ewes (EAE). C. abortus is a Gramnegative bacterium with the characteristic of obligate intracellular relationship (Seth-Smith et al. 2017). Chlamydiosis causes acute placentitis and abortion in advance pregnancy, particularly in the last 2 to 3 weeks of gestation. There may be stillbirth or birth of weak lamb(s) if abortion does not occur (Aitken and Longbottom 2007). There are no specific symptoms or clinical expressions of the disease. Behavioral changes and vulvar discharge may be seen before abortion in some cases. The prominent sign of this disease is the expulsion of dead or weak lambs, peculiarly 2-3 weeks before expected lambing. The lambs usually look mature and normal but, in some cases, there may be 'pot-bellied' lambs due to subcutaneous edema. Moreover, in some cases, lamb fleece may also be covered with exudate, which is creamy pink, brown in appearance (Maley et al. 2009). However, sometimes lambs are born to live but prematurely, and are enough weak to survive beyond 24 hours. In this disease, the vaginal discharge and placenta are highly infectious, with placenta having dirty pinkish and reddish-yellow-colored exudates on its surface. Metritis, especially in goats, may also be found in this disease due to retention of placenta, which mainly is due to secondary bacterial infection. Abortion before 2-3 weeks of expected lambing could be the first detecting sign (Selim 2016). The environment is contaminated by uterine discharge and fetal fluids and the organisms are shed in the infected placenta.

Transmission of Chlamydiosis occurs through ingestion and inhalation of organisms from the contaminated material and environment (Navarro et al. 2004). The exact pathogenesis is still unknown. However, it is suggested that the organisms colonize in the trophoblast cells of the fetal cotyledons and spread the infection to the inter-cotyledon area of the chorion to produce necrotic placentitis and edema. This causes characteristic thickening of the placental membranes and cotyledons which impairs the exchange of nutrients and oxygen between fetus and mother (Buxton et al. 2002). Moreover, there are disturbances in the blood progesterone levels that lead to abortion (Soomro et al. 2015). The organisms may reside in lymphoid tissue in the latent or silent form in non-pregnant animals until the onset of pregnancy. The pathological changes in the placenta start to develop after 90 days of gestation but the infection remains subclinical (Essig and Longbottom 2015).

The products of abortions are sources of contamination for the environment and susceptible animals, as well as humans. The organisms can be found in large numbers in the vaginal fluids, placenta, and fleece of dead lambs. The live lambs may be carriers and a risk factor for naive sheep and goats (Caspe et al. 2020). The animals with abortion in their last pregnancy due to $C$. abortus may shed this infectious bacterium amid both the subsequent periovulation period and at the time of their next lambing, while this risk is minimal as proved by the latest molecular studies. The risk of venereal transmission by males is very low and has relatively no role in the spread of the disease. Although vertical transmission in ewes is possible but horizontal transmission has great havoc for susceptible animals. An aborting ewe can infect other pregnant ewes, however, the animals infected after 110120 days of gestation will normally complete their gestation length.

Several Chlamydial species that belong to the genus Chlamydia and family Chlamydiaceae can cause various infectious diseases in humans, other mammals, and birds. Different species of genus Chlamydia can cause respiratory illness and reproductive problems in men (Joseph et al. 2015). In animals, they can cause abortion, keratoconjunctivitis, infertility, and respiratory disease (Girjes et al. 1988). As the diagnosis of the disease is not confirmatory, precautions should be taken to minimize the risk of infection for the ewes and humans.

The serological diagnosis in the past was mainly based on CFT, but it is less sensitive and less specific due to crossreaction with other gram-negative bacteria and other Chlamydia species like Chlamydia pecorum having LPS antigens. At present, more sensitive and more specific serological ELISA-based test has been developed which uses major outer membrane protein (MOMP) and polymorphic outer membrane protein (POMP). 
Table 1: Prevalence of Chlamydia abortus with different diagnostic techniques

\begin{tabular}{|c|c|c|c|c|c|}
\hline \multirow[t]{2}{*}{ Country } & \multicolumn{3}{|c|}{ Prevalence percentage } & \multirow{2}{*}{$\begin{array}{l}\text { The method } \\
\text { for diagnosis }\end{array}$} & \multirow[t]{2}{*}{ used Reference } \\
\hline & Tested & Positive & $\%$ & & \\
\hline Bosnia and Herzegovina & 178 & 77 & $43 \cdot 3$ & ELISA & Krkalić et al. (2016) \\
\hline Ireland & 201 & 42 & $20.9 \%$ & ELISA & O'Donovan and Forsythe (2015) \\
\hline Iraq & 124 & 12 & $11.1 \%$ & ELISA & Fahad and Salman (2017) \\
\hline Jordan & 25 & 13 & $52 \%$ & IHC and PCR & Hailat et al. (2018) \\
\hline Saudi Arabia & 399 & 30 & $7 \%$ & ELISA & Aljumaah and Hussein (2012) \\
\hline Turkey & 71 & 7 & $9.8 \%$ & PCR & Kalender et al. ( 2013) \\
\hline Iran & 364 & 20 & $5 \cdot 71 \%$ & ELISA & Borujeni et al. (2019) \\
\hline \multirow[t]{3}{*}{ Mexico } & 246 & 12 & $4.9 \%$ & ELISA & Campos-Hernández et al. (2014) \\
\hline & 801 & 118 & 14.73\% (Himachal Pradesh) & & \\
\hline & 1221 & 60 & 4.91\% (Andhra Pradesh) & & \\
\hline India & 24 & 3 & $12.5 \%$ (Jammu and Kashmir) & AGPT & Chahota et al. (2015) \\
\hline Belgium & 958 & 38 & $4.05 \%$ & ELISA & Yin et al. (2014) \\
\hline Egypt & 675 & 93 & $13.7 \%$ & ELISA & Selim et al. (2021) \\
\hline China & 1732 & 323 & $18.65 \%$ & IHA & Qin et al. (2014) \\
\hline Saxony (Germany) & 1714 & 259 & $15.1 \%$ & ELISA & Runge et al. (2012) \\
\hline Italy & 27 & 3 & $11.1 \%$ & PCR & Greco et al. (2005) \\
\hline Algeria & 144 & 51 & $35.4 \%$ & ELISA & Merdja et al. (2015) \\
\hline Costa Rica & 359 & 19 & 5.29 & ELISA & Villagra-Blanco et al. (2015) \\
\hline Switzerland & 235 & 10 & $4.2 \%$ & PCR & Borel et al. (2006) \\
\hline Taiwan & 112 & 37 & $33.3 \%$ & PCR & Wang et al. (2001) \\
\hline
\end{tabular}

Table 2: Human infections of Chlamydia abortus

\begin{tabular}{|c|c|c|c|c|c|}
\hline $\begin{array}{l}\text { Serial } \\
\text { No. }\end{array}$ & $\begin{array}{l}\text { Gender } \\
\text { infected }\end{array}$ & $\begin{array}{l}\text { Pregnancy } \\
\text { duration }\end{array}$ & Symptoms & Reference & Country \\
\hline 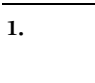 & Female 22 & $24^{\text {th }}$ week & $\begin{array}{l}\text { Fever, headache, heartburn, shivering, sweating, vomiting } \\
\text { abortion }\end{array}$ & (Roberts et al. 1967) & UK \\
\hline 2. & Female 28 & $28^{\text {th }}$ week & Fever, influenza-like illness, shock, renal failure, DIC, stillbirth & (Wong et al. 1985) & UK \\
\hline 3. & Female 25 & $\begin{array}{l}\text { Not } \\
\text { available }\end{array}$ & Fever, dry cough, fatigue, malaise, Pneumonia & $\begin{array}{l}\text { (Hyde and Benirschke } \\
\text { 1997) }\end{array}$ & USA \\
\hline 4. & Female 20 & $26^{\text {th }}$ week & Sepsis, respiratory distress, Preterm fetal loss & ipinga et al. 2000) & Netherlands \\
\hline 5 . & Female 39 & $\begin{array}{l}\text { Non- } \\
\text { pregnant }\end{array}$ & $\begin{array}{l}\text { Lower abdominal pain, fatigue, intermittent fever, irregula } \\
\text { menstrual cycle, hypochromic anemia, previous miscarriages }\end{array}$ & (Walder et al. 2003) & Aus \\
\hline 6. & Female 29 & $25^{\text {th }}$ week & $\begin{array}{l}\text { Abdominal pain, headache, dry cough, malaise, fever, renal anc } \\
\text { hepatic dysfunction, leukocytopenia, thrombocytopenia, anc } \\
\text { Increase C-reactive, Stillbirth }\end{array}$ & (Meijer et al. 2004) & Nethe \\
\hline 7 . & Female 32 & $16^{\text {th }}$ week & $\begin{array}{l}\text { High fever, Septicemia, dyspnea, Pneumonia, increase C-reactiv } \\
\text { thrombocytopenia, fetal death }\end{array}$ & (Walder et al. 2005) & Italy \\
\hline 8. & Female & $31^{\text {st }}$ week & $\begin{array}{l}\text { Fever, septic shock, respiratory distress, multiple organ failure } \\
\text { premature delivery }\end{array}$ & (Janssen et al. 2006) & Netherlands \\
\hline & & NA & Respiratory distress, & & \\
\hline & Female 27 & $23^{\text {rd }}$ week & Headache, cough, fever, in utero fetal death & (Pichon et al. 2020) & France \\
\hline
\end{tabular}

\section{Prevalence}

Chlamydia abortus is prevalent worldwide and is a major cause of abortion in sheep in many countries. Prevalence of Chlamydia abortus in different geographic regions of the world is shown in Fig. 1 and Table 1.

\section{Transmission}

Its unique biphasic developmental cycle has morphologically and functionally two different chlamydial forms; 1) an Elementary body that attaches to the eukaryotic host cell and initiates infection; 2) a Reticulate body. After getting entry into the host cell, the elementary body converts into the reticulate body, which is non-infectious but metabolically active. Reticulate bodies start to multiply by asexual binary fission in nonfusogenic vacuoles, which are also named as inclusions (Marschall et al. 2020). These elementary bodies keep growing until inclusions fill the cytoplasm of the host cell. Within 24-48 hrs, elementary bodies start to re-convert into reticulate bodies, which are then released from the host cell and may cause infection in nearby cells (Longbottom et al. 2019).

Aborted ewes are the main source of Chlamydial transmission to other animals (Pellerin et al. 2019). The product of abortion (uterine discharge, fetus, placental membranes, fetal fluids) are risk factors for the contamination of the environment. Such an environment is highly infectious for the naive ewes ( $\mathrm{Li}$ et al. 2018). So, the new animals are at greater risk in such an environment. The organism may survive in the environment for several days under favorable climate (Gitsels et al. 2020).

The overwhelming courses of transmission can vary between Chlamydial species, infection disorders, and hosts. C. abortus is regularly transmitted to other creatures through aborted material; it can also spread 


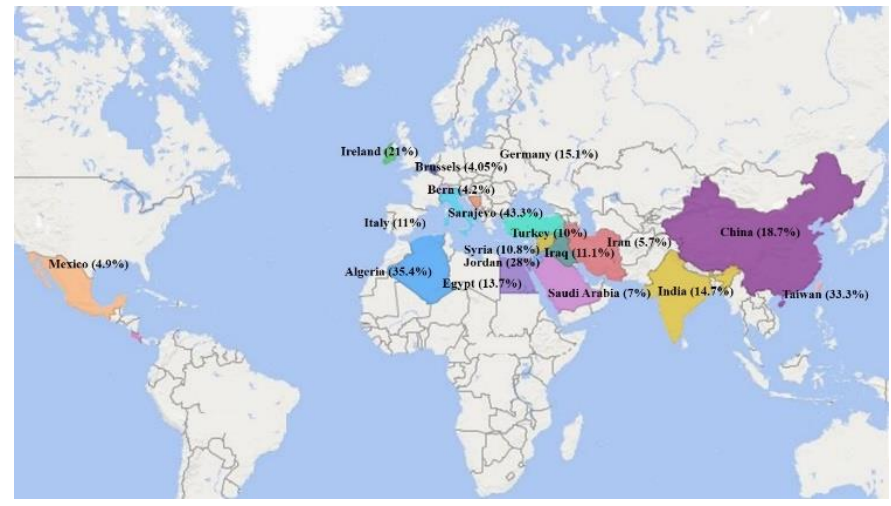

Fig. 1: GIS mapping of the prevalence of Chlamydiosis in different countries. infected materials (Longbottom and Coulter 2003; Sillis and Longbottom 2011). As most of the reported cases of C. abortus in humans have been through direct or indirect contact with animals, especially those with a history of abortion due to Chlamydial infection, women in pastoralist families must take precautionary measures while approaching the animals, especially during lambing season (Meijer et al. 2004: Essig and Longbottom 2015). The infection in humans is mostly associated with pneumonia, pulmonary edema, and placentitis. Histologically, inter-villositis and the presence of Chlamydial inclusion bodies in the placental trophoblasts are the most characteristic findings (Essig and Longbottom 2015). A review of clinical symptoms observed in most of the reported cases is presented in Table 2.

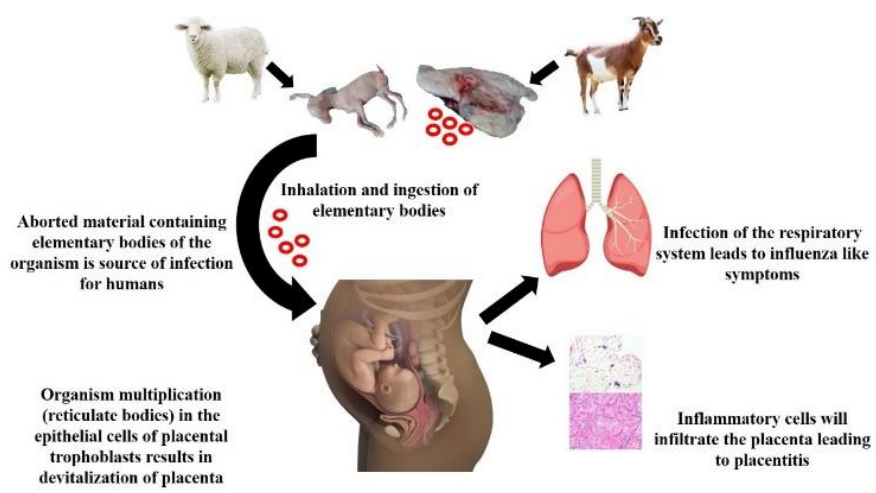

Fig. 2: Transmission of Chlamydia abortus from animals to humans.

through other secretions and excretions like feces, etc. Pregnant ruminants can shed a huge number of $\mathrm{C}$. abortus within the placenta and vaginal liquids during normal and abnormal births. Shedding of a pathogen in vaginal fluid starts within two weeks before abortion of fetus especially in goats and may continue (often discontinuously) for many weeks afterward. Sheep and goats can be carriers of C. abortus, which cause persistent infection in sheep for at least 2-3 years. A few studies have reported that this organism can also be shed in small quantities at the time of estrus and during subsequent pregnancies of animals.

Aborted fetal membranes and fluids are the main sources of spreading infection. Transfer of this pathogen to susceptible ewes occurs after consumption of contaminated feed and water with aborted fluids and tissues (Arif et al. 2020). After ingestion, this infective agent can cause abortion within about 60 to 90 days and sometimes ewes that become infected late in the gestation period may give birth to weak lambs (Sargison et al. 2015). Once the aborted ewes recover, they show no signs of sickness, unless the secondary infection occurs. The weak-born lambs should be isolated from the healthy herd, as they are also a source of infection for the susceptible animals. The infection becomes latent in healthy sheep and goats, without causing any illness until the next pregnancy and leads to abortion in the last month.

Aborting sheep can also be an infectious risk for the other pregnant sheep in the same lambing season, while the ewes which get infected in the last 1-2 months of pregnancy usually go on to normal delivery (Laroucau et al. 2018).

\section{Pathogenesis}

Chlamydia abortus is recognized as the main cause of abortion in the late-term pregnancy of sheep and goats. The other symptoms of Chlamydia abortus infection in sheep are conjunctivitis and other health pathologies (Singh et al. 2017). The organism gets into the body mainly through inhalation and rarely through ingestion or abrasions. It spreads to other body organs through blood or lymph. Initially, the organism affects the tonsils and nearby lymph nodes, causing inflammation of these organs, and resulting in the necrosis of cells. It shows biphasic development in the host cell (Essig and Longbottom 2015). It enters the host cell in the form of an elementary body (EB) and is converted to a reticulate body (RB), which is replicating and metabolically active but noninfectious stage and resides intra-cellularly as cytoplasmic inclusions bonded by lipid membranes. The cell cytoplasm becomes filled by these replicating vacuoles and RB re-condenses to EBs (Wheelhouse et al. 2012). The cell bursts, releasing the pathogens to infect the other cells (Wheelhouse et al. 2012).

The Chlamydia abortus presents a specific type of proteins named polymorphic membrane proteins (Pmps), also known as autotransporters (ATs), which are strongly immunogenic and cause the release of inflammatory mediators from cells. These proteins are of great importance in comprehending the pathogenesis and virulence of the organism (Wheelhouse et al. 2012). The fact that the infection with Chlamydia abortus before pregnancy or in early pregnancy does not show any clinical signs and remains latent can be correlated with the activation of the immune system of the host due to the high immunogenicity of these specific proteins. The infection during pregnancy becomes apparent due to the suppression of the immune mechanism of the body (Longbottom et al. 2013).

The clinical manifestation of Chlamydial infection is mainly characterized by placentitis, which leads to various complications such as septicemia, stillbirth, and abortion in advanced stages of pregnancy (Pan et al. 2017). As the ewes get pregnant, the latent infection reappears and triggers subclinical Chlamydiosis (Essig and Longbottom 2015). This leads to the infection and inflammation in the placental trophoblasts of chorionic 
villi. The growth and pathogenesis of $C$. abortus are not obvious till day 90 of the pregnancy. The infection increases following the advancement of the pregnancy. The infection in the placenta may be correlated to the formation of hematoma in chorionic villi of the placenta (Essig and Longbottom 2015). The cause of these hematomas is the release of blood from capillaries in the hilus of ovine placentomes. The organism gets access to the trophoblastic epithelial cells through this route where they proliferate, and cytoplasmic inclusion bodies are produced. Inflammation and edema are produced in the placentomes and inter-cotyledonary tissues when the infection spreads to the surrounding tissues of the placentomes. The cotyledons and placental membranes appear reddened and thickened in response to the infection (Essig and Longbottom 2015; Caspe et al. 2020). The exact mechanism of the abortion by Chlamydia abortus is not fully understood, however, one of the possible causes can be the devastation of the chorionic epithelium and placental membranes, leading to the mutilation of the function of placentomes and impairing the transport of oxygen and nutrients during the maternal-fetal exchange. The other possible underlying cause is the decrease in the release of progesterone in the infected dam. Progesterone is the main pregnancy hormone in the pregnant ewe and is mainly produced from epithelial cells of the chorionic villi. The progesterone release is decreased in response to the damage of these cells. The local production of $\mathrm{PGE}_{2}$ and estradiol is increased (Caspe et al. 2020; Essig and Longbottom 2015). The inflammatory mediators, such as tumor necrosis factor and interleukin, are produced from the trophoblastic cells, causing the inflammation. The interaction of these hormones and mediators leads to early induction of parturition, resulting in premature birth or abortion. The organism also affects the liver, lungs, and brain of the fetus, impairing the function of these organs (Essig and Longbottom 2015).

\section{Lesions}

Grossly, the placental tissue shows purulent to necrotic placentitis. There is edema and hemorrhages of the placenta along with the presence of necrotic foci and purulent exudate in the cotyledons (Borel et al., 2018). Dissemination of infection to fetal tissues results in necrotic and inflammatory lesions in multiple fetal organs. Histo-pathological examination shows the necrosuppurative placentitis with the infiltration of inflammatory cells, including neutrophils, monocytes, and macrophages (Livingstone et al. 2017). There is evidence of vasculitis and thrombosis in the inter-cotyledonary membranes. The mononuclear cells also invade and can be seen in the inflammatory exudate and affected arteries and arterioles (Essig and Longbottom 2015).

\section{Diagnosis}

There is no specific or characteristic sign of this disease, as the infection remains undetected. There may be vulvar discharge and behavioral changes just before the abortion, but this is not a specific sign (Villagra-Blanco et al. 2015). In some cases, there may be thickened cotyledonary membranes with reddish appearance due to edema having viscous creamy exudate, while in some cases inflamed and necrotic placenta can also be observed. These signs may be confused with other abortion-causing pathogens; therefore, laboratory confirmation is required for the exact diagnosis of Chlamydia abortus (Livingstone et al. 2017). The tumor necrosis factor can play a major role in the progression of abortion (Buxton et al. 2002).

The PCR and ZN staining can't detect infectious agents, as the excretion of the pathogens till the onset of abortion and maternal antibodies to $C$. abortus rapidly increase to develop the protective immunity. There are distinctive strategies for the clinical diagnosis of $C$. abortus. Serological detection is done by immunological techniques, like complement fixation test (CFT) and enzyme-linked immunosorbent assay (ELISA) (Rekiki et al. 2006).

Several methods and tests have been developed for the laboratory diagnosis of $C$. abortus; these are based on serum evaluation of aborted animals, examination of tissues taken from the aborted fetuses and other abortion products. Isolation and culture of the organism are highly reliable method, but it requires proper facilities and skillful expertise (Opota et al. 2015). Complement fixation test (CFT) is widely used for the serological diagnosis of Chlamydia abortus, but it tends to show higher sensitivity for the other gram-negative organisms like $C$. pecorum. Therefore, results can be confusing with other gramnegative organisms due to their low specificity (McCauley et al. 2007). Tissue samples from the fetus and placenta can be used for the isolation and identification of $C$. abortus, using Giemsa and immunohistochemical staining and specific monoclonal antibodies (Sargison et al. 2015). ELISA-based serological tests are now being used for the diagnosis of Chlamydia abortus. Blood samples from animals having a history of abortion are collected for ELISA-based serological assays. These assays detect the anti-chlamydial antibodies in serum. These tests use specific antigen proteins like MOMP (major outer membrane protein) and POMP (polymorphic outer membrane protein) for the identification of $C$. abortus (Livingstone et al. 2005) and to minimize the chances of cross-reactivity.

DNA of Chlamydia abortus can be detected through PCR by using vaginal swabs, aborted fetuses, placental tissues, and other fetal tissues. The organisms are present in large numbers in the abortion material and vaginal exudates. Vaginal swabs have some advantages to be used for PCR. Inoculation of organisms in chicken eggs is also used to identify the Chlamydia DNA (Kalender et al. 2013).

Polymerase chain reaction (PCR) is another new reliable method for the identification of $C$. abortus (CamposHernández et al. 2014). Recently, real-time PCR has become the technique of choice for many diagnostic laboratories due to its rapidity, sensitivity, and ease of standardization. This method is rapid, as culturing of 
organisms is not essential for diagnosis (Santoro et al. 2019). PCR detects the Chlamydial DNA by targeting different components of the genome. Outer membrane proteins (ompA), including omp1, omp2, and amplification of pleomorphic genes enables the detection of Chlamydia through PCR. Moreover, detection of Chlamydia abortus has been achieved through other components, like genes encoding 16S RNA, helicase, and 16S-rRNA. There may be some problems due to which results may be false negative or isolation cannot be achieved if the samples are taken during the pregnancy or vaginal swabs are taken after many days. At the time of abortion, sampling gives remarkable results for isolation and identification the organism. PCR-mediated recognition of $C$. abortus may not relate to fruitful isolation and culture of the bacteria from tissue samples at all times (Kalender et al. 2013).

\section{Zoonosis}

Human infections of $C$. abortus may be acquired from contaminated items of premature birth, parturition or carelessly processing laboratory cultures of the organism. Women involved in handling the livestock, especially the aborted animals, are at high risk of acquiring the infection. Besides causing generalized septicemia, the organism is capable of inducing stillbirth or abortion in pregnant women (Pospischil et al. 2002). Approximately 94\% cases of animal acquired Chlamydiosis result in fetal loss and $6.3 \%$ in maternal death. Clinical signs vary from the acute febrile condition, respiratory distress, fatigue, malaise, liver, and kidney function failure to shock, disseminated intravascular coagulopathy, and death (Katsura et al. 2020). Some authors have reported "influenza-like illness", terminating in fetal death, in pregnant females. The Chlamydial organism reaches the placenta, and multiplies in the epithelial cells of the trophoblasts, which damages the placental vitality. The level of C-reactive protein is raised, along with a decrease in platelet count in the infected females (Pichon et al. 2020). In non-pregnant females, the infection is associated with the development of "pelvic inflammatory disease" (Walder et al. 2003). A recent review reported that out of 23 cases of gestational Chlamydiosis, 20 were acquired from sheep and goats (Katsura et al. 2020). A case of atypical pneumonia in a veterinary researcher has been associated with C. abortus (Ortega et al. 2016). Therefore, biorisk management should be adopted during the handling of culture and potentially

\section{Prevention and Control}

\section{Management of flock}

It is an important aspect to control this disease, as it causes great zoonotic and economical losses. It spreads from animal to animal; horizontal transmission occurs in a herd and also from animal to humans by direct contact with aborted fetal material. For the prevention of $C$. abortus, one should take strict measures like isolation of seropositive animals from the rest of the herd/flock. Animals with recent abortion history should be kept isolated until their uterine discharge is completely dried up (approximately in 7-10 days). The disposal of infected dead fetal membranes or bedding should be properly buried or incinerated out. The infected place or bunkers should be properly disinfected and thoroughly cleaned (Robertson et al. 2018).

The veterinarian or flock manager should use his protective equipment during handling of infected animals and materials. Health workers should not use the same PPE to handle other animals, until proper disinfection of PPE is done to reduce the risk of spreading the disease in healthy animals, as the infected animals may shed organisms (Zezekalo et al. 2020). Purchasing new animals should be from a reliable source. The introduction of newly bought animals in the flock should be done after serological testing from a trusted laboratory.

\section{Antibiotic treatment}

Seropositive animals should be isolated from rest of the herd and provided supportive treatment, such as multivitamins or minerals, to reduce the severity of the infection. Antimicrobial susceptibility tests have shown that macrolides and tetracycline $(20 \mathrm{mg} / \mathrm{kg})$ can be used for treatment (Barhoom 2015). The mode of action of antichlamydial antibiotics is through inhibition of the Chlamydial protein synthesis by binding to the $30 \mathrm{~S}$ ribosomal subunit (Bommana and Polkinghorne 2019). Treatment should be given on the first onset of clinical signs (if any sign appears). Single-dose of long-acting antibiotics minimizes severity of the disease. But such antibiotic therapy does not recover the animal completely or reverse any pathological changes that had occurred. It has also been reported that routine oral administration of tetracycline (400-500 $\mathrm{mg}$ ) fortnightly can reduce the shedding of Chlamydia in the lambing season. This also reduces degree of contamination of the environment and farms. The best way of controlling the disease is the combined use of antibiotics, vaccination, and proper herd management (Longbottom et al. 2013).

\section{Vaccination}

The control of $C$. abortus infection has been focused on the vaccination protocol to minimize the abortion rate and excretion of the organism. For $C$. abortus, both attenuated and live vaccines, having origin from different countries, are available in the market. Commercially available live attenuated vaccine, which has strain $C$. abortus (temperature-sensitive), shows good results (O'Neill et al. 2019). But it is compulsory to maintain the cold chain of vaccines for best performance against infection. It is also observed that vaccines may induce the disease and abortion (Caspe et al. 2020). The vaccine should be administered 4 weeks before mating and antibiotics should not be administered with the living vaccine. The inactivated vaccine, prepared on embryonated eggs or cell culture, is also available. Now-a- 
days, scientists are focusing on preparing vaccines with different strains that would be easy to handle, cheap and safe to administer in animals.

A vaccination trial of a commercially available, inactivated vaccine at different doses revealed that there was no significant difference between the control group and the vaccinated groups after the administration. The vaccine showed favorable effects on the birth weight and weight gain in lambs during the first 30 days of their life (García-Seco et al. 2016).

Live attenuated vaccine of Chlamydial strain $1 \mathrm{~B}$ has been seen to induce abortion in the ewes, as the same strain was isolated from the aborted fetuses and other abortion material. This study showed that $1 \mathrm{~B}$ strain may not be properly attenuated and has a risk for induction of abortion. There should be the repetition of live vaccine after every 2-3 years and the administration of inactivated vaccine should be done annually. Now-a-days, research on the vaccine is focused to develop more effective, cheap, stable and safe vaccines, which may not cause disease in animals and have a good ability to produce sterile protective immunity.

\section{Disinfection}

Cleaning and sterilization, together with individual cleanliness (e.g., hand washing, cleaning/disinfection of footwear) are important in preventing the spread of fomites. Aborting animals with Chlamydiosis should be separated because they are the risk of infecting others. Abortion or birth products from infected animals should be removed, and the area should be cleaned and disinfected. Most strains of Chlamydia are susceptible to many available disinfectants. Chlamydia is inactivated in the presence of sodium hypochlorite, glutaraldehyde, 70\% ethanol, peracetic acid, and also in the presence of Quaternary ammonia. It is resistant to some alkalis and acids. Like some bacteria, application of moist heat having a temperature of $121 \mathrm{C}^{\circ}$ for 15 minutes and dry heat at ${ }^{160}-170 \mathrm{C}^{\circ}$ for one hour can cease the biological activity of Chlamydia.

Concluding remarks: The global distribution of Chlamydial bacteria infections and its sharing at the animal-human-environment interface suggest an urgent need for interdisciplinary approach, such as One Health, to control this neglected disease. Various pathogenic species of Chlamydia are associated with zoonotic transmission to humans and adverse public health outcomes or losses. There is a dire need to circumvent drug resistance in Chlamydia and the development of protective vaccines for animals and humans. Awareness, containment, and community education would be indispensable to mitigate occupational risk and dissemination of Chlamydial pathogens at the animalhuman nexus.

\section{REFERENCES}

Aitken I and Longbottom D, 2007. Chlamydial abortion. In: Diseases of Sheep. I. Aitken (ed.) $4^{\text {th }}$ Edition, pp.
105-112.

Aljumaah RS and Hussein MF, 2012. Serological prevalence of ovine and caprine Chlamydophilosis in Riyadh region, Saudi Arabia. African Journal of Microbiology Research 6: 2654-2658.

Arif et al., 2020. Isolation and identification of Chlamydia abortus from aborted ewes in Sulaimani province, Northern Iraq. Polish Journal of Microbiology 69: 6571.

Barhoom S, 2015. Enzootic abortion of ewes (Ovine Chlamydiosis): Diagnosis and control. IUG Journal of Natural Studies 15: 15-19.

Bommana S and Polkinghorne A, 2019. Antimicrobial control of Chlamydial infections in animals: Current practices and issues. Frontiers in Microbiology 10: Article \# 113.

Borel et al., 2006. Chlamydia-related abortions in cattle from Graubunden, Switzerland. Veterinary Pathology 43: 702-708.

Borel et al., 2018. A Review on Chlamydial diseases in animals: Still a challenge for pathologists? Veterinary Pathology 55: 374-39o.

Borujeni et al., 2019. Chlamydia abortus infection in goats in the southwest of Iran. Revue de Medecine Veterinaire 170: 9-14.

Buxton et al., 2002. Ovine Chlamydial abortion: characterization of the inflammatory immune response in placental tissues. Journal of Comparative Pathology 127: 133-141.

Campos-Hernández et al., 2014. Prevalence and molecular identification of Chlamydia abortus in commercial dairy goat farms in a hot region in Mexico. Tropical Animal Health and Production 46: 919-924.

Caspe et al., 2020. The $1 \mathrm{~B}$ vaccine strain of Chlamydia abortus produces placental pathology indistinguishable from a wild type infection. PLOS ONE 15: Article \# 0242526.

Chahota et al., 2015. Seroprevalence studies on animal Chlamydiosis amongst ruminants in five states of India. Veterinary World 8: 72-75.

Essig A and Longbottom D, 2015. Chlamydia abortus: New aspects of infectious abortion in sheep and potential risk for pregnant women. Current Clinical Microbiology Reports 2: 22-34.

Fahad OA and Salman SS, 2017. Survey for ovine and caprine Chlamydiosis by ELISA in AL-Fallujah city/Iraq. Journal of Entomology and Zoology Studies 5: 322-326.

García-Seco et al., 2016. Effect of preventive Chlamydia abortus vaccination in offspring development in sheep challenged experimentally. Frontiers in Veterinary Science 3: Article \# 67.

Girjes et al., 1988. Two distinct forms of Chlamydia psittaci associated with disease and infertility in Phascolarctos cinereus (koala). Infection and Immunity 56: 1897-1900.

Gitsels et al., 2020. Chlamydia: what is on the outside does matter. Critical Reviews in Microbiology 46: 100119. 
Greco et al., 2005. Detection of Chlamydophila abortus in sheep and goat flocks in southern Italy by PCR using four different primer sets. Veterinary Research Communications 29: 107-115.

Hailat et al., 2018. Pathological, immunohistochemical and molecular diagnosis of abortions in small ruminants in Jordan with reference to Chlamydia abortus and Brucella melitensis. Pakistan Veterinary Journal 38: 109-112.

Hyde SR and Benirschke K, 1997. Gestational psittacosis: Case report and literature review. Modern Pathology: An Official Journal of the United States and Canadian Academy of Pathology 10: 602-607.

Janssen et al., 2006. Sepsis due to gestational psittacosis: A multidisciplinary approach within a perinatological center--review of reported cases. International Journal of Fertility and Women's Medicine 51: 17-20.

Joseph et al., 2015. Chlamydiaceae genomics reveals interspecies admixture and the recent evolution of Chlamydia abortus infecting lower mammalian species and humans. Genome Biology and Evolution 7: 3070-3084.

Kalender et al., 2013. Identification of Chlamydophila abortus infection in aborting ewes and goats in Eastern Turkey. Revue de Medecine Veterinaire 164: 295-301.

Kampinga et al., 200o. Lambing ewes as a source of severe psittacosis in a pregnant woman. Nederlands Tijdschrift voor Geneeskunde 144: 2500-2504.

Katsura et al., 2020. Gestational psittacosis: A case report and literature review. Journal of Obstetrics and Gynaecology Research 46: 673-677.

Krkalić L et al., 2016. Seroprevalence of Chlamydia abortus in sheep in Bosnia and Herzegovina. Veterinarski arhiv 86: 373-381.

Laroucau et al., 2018. Abortion storm induced by the live C. abortus vaccine $1 \mathrm{~B}$ strain in a vaccinated sheep flock, mimicking a natural wild-type infection. Veterinary Microbiology 225: 31-33.

Li et al., 2018. First report of Chlamydia abortus in farmed fur animals. BioMed Research International 2018: Article \# 4289648 .

Livingstone et al., 2005. Antibody responses to recombinant protein fragments of the major outer membrane protein and polymorphic outer membrane protein POMP9o in Chlamydophila abortus-infected pregnant sheep. Clinical and Diagnostic Laboratory Immunology 12: 770-777.

Livingstone et al., 2017. Pathogenic outcome following experimental infection of sheep with Chlamydia abortus variant strains LLG and POS. PLOS ONE 12: Article \# 0177653.

Longbottom D and Coulter LJ, 2003. Animal Chlamydiosis and zoonotic implications. Journal of Comparative Pathology 128: 217-244.

Longbottom et al., 2013. Evaluation of the impact and control of enzootic abortion of ewes. The Veterinary Journal 195: 257-259.

Longbottom et al., 2019. Proteomic characterisation of the Chlamydia abortus outer membrane complex
(COMC) using combined rapid monolithic column liquid chromatography and fast MS/MS scanning. PLOS ONE 14: Article \# 0224070.

Longbottom et al., 2013. Intranasal infection with Chlamydia abortus induces dose-dependent latency and abortion in sheep. PLOS ONE 8(2): Article \# 57950.

Maley et al., 2009. Identification of Chlamydophila abortus and the development of lesions in placental tissues of experimentally infected sheep. Veterinary Microbiology 135: 122-127.

Marschall et al., 2020. The putative type III secreted Chlamydia abortus virulence-associated protein $\mathrm{CABo6}_{3}$ targets lamin and induces apoptosis. Frontiers in Microbiology 11: Article \# 1059.

McCauley et al., 2007. Comparison of ELISA and CFT assays for Chlamydophila abortus antibodies in ovine sera. Australian Veterinary Journal 85: 325-328.

Meijer et al., 2004. Chlamydophila abortus infection in a pregnant woman associated with indirect contact with infected goats. European Journal of Clinical Microbiology and Infectious Diseases 23: 487-490.

Merdja et al., 2015. Chlamydial abortion in Algerian small ruminants. Bulletin UASVM Veterinary Medicine 72: 23-26.

Navarro et al., 2004. Kinetics of infection and effects on the placenta of Chlamydophila abortus in experimentally infected pregnant ewes. Veterinary Pathology 41: 498-505.

O'Donovan J and Forsythe C, 2015. Ovine abortion. In: All-Island Animal Disease Surveillance Report. John Fagan (ed). A Joint AFBI/DAFM Laboratories Publication, Ireland. 42-43.

O'Neill et al., 2019. Evaluation of protective and immune responses following vaccination with recombinant MIP and CPAF from Chlamydia abortus as novel vaccines for enzootic abortion of ewes. Vaccine 37: 5428-5438.

Opota et al., 2015. Improving the molecular diagnosis of Chlamydia psittaci and Chlamydia abortus infection with a species-specific duplex real-time PCR. Journal of Medical Microbiology 64: 1174-1185.

Ortega $\mathrm{N}$ et al.,2016. Isolation of Chlamydia abortus from a laboratory worker diagnosed with atypical pneumonia. Irish Veterinary Journal 69: 8.

Pan et al., 2017. Chlamydia abortus Pmp18.1 induces IL-1 $\beta$ secretion by TLR4 activation through the MyD88, NF-KB, and Caspase-1 signaling pathways. Frontiers in Cellular and Infection Microbiology 7: Article \# 514.

Pellerin et al., 2019. Risk of Chlamydia abortus transmission via embryo transfer using in vitro produced early bovine embryos. Theriogenology 126 : 114-120.

Pichon et al., 2020. Chlamydia abortus in pregnant woman with acute respiratory distress syndrome. Emerging Infectious Diseases 26: 628-629.

Pospischil et al., 2002. Abortion in women caused by caprine Chlamydophila abortus (Chlamydia psittaci serovar 1). Swiss Medical Weekly 132: 64-66. 
Qin et al., 2014. Seroprevalence and risk factors of Chlamydia abortus infection in Tibetan sheep in Gansu province, northwest China. The Scientific World Journal 2014: Article \# 193464.

Rekiki et al., 2006. Comparative evaluation of a new commercial recombinant ELISA and the complement fixation test for the diagnosis of Chlamydophila abortus infection in naturally infected flocks in Tunisia. Small Ruminant Research 66: 58-63.

Roberts et al., 1967. Human abortion associated with infection by ovine abortion agent. British Medical Journal 4: 37.

Robertson et al., 2018. General evaluation of the economic impact of introduction of Chlamydia abortus to a Scottish sheep flock. Veterinary Record Case Reports 6: Article \# ooo689.

Runge et al., 2012. Investigations concerning the prevalence of Coxiella burnetii and Chlamydia abortus in sheep in correlation with management systems and abortion rate in Lower Saxony in 2004. Berliner und Münchener Tierärztliche Wochenschrift 125: 10-15.

Sachse et al., 2015. Emendation of the family Chlamydiaceae: proposal of a single genus, Chlamydia to include all currently recognized species. Systematic and Applied Microbiology 38: 99-103.

Santoro et al., 2019. Molecular detection of Chlamydia abortus in a stranded Mediterranean striped dolphin Stenellacoeruleoalba. Diseases of Aquatic Organisms 132: 203-208.

Sargison et al., 2015. Identification of the $1 B$ vaccine strain of Chlamydia abortus in aborted placentas during the investigation of toxemic and systemic disease in sheep. New Zealand Veterinary Journal 63: 284-287.

Selim A, 2016. Chlamydophila abortus infection in small ruminants: A review. Asian Journal of Animal and Veterinary Advances 11: 587-593.

Selim et al., 2021. Seroprevalence, associated risk factors analysis and first molecular characterization of chlamydia abortus among Egyptian sheep. Comparative Immunology, Microbiology and Infectious Diseases 74: Article \# 101600.

Seth-Smith et al., 2017. European Chlamydia abortus livestock isolate genomes reveal unusual stability and limited diversity, reflected in geographical signatures. BMC Genomics 18: 1-10.

Sillis $\mathrm{M}$ and Longbottom D, 2011. Chlamydiosis. In: Palmer SR, Soulsby L, Torgerson PR and Brown DWG (eds). Zoonoses. $2^{\text {nd }}$ Edition, Oxford University Press, Oxford, UK; pp. 146-157.

Singh et al., 2017. In silico functional elucidation of uncharacterized proteins of Chlamydia abortus strain LLG. Future Science OA3: Article \# FSO169.

Soomro et al., 2015. In-vitro growth of Chlamydophila abortus in ovine endometrium: Evidence of growth support in stromal fibroblast cells. Pakistan Journal of Agriculture 31: 115-126.

Villagra-Blanco et al., 2015. Detection of antibodies against Chlamydophila abortus in Costa Rican sheep flocks. Open Veterinary Journal 5: 122-126.

Walder et al., 2005. An unusual cause of sepsis during pregnancy: recognizing infection with chlamydophila abortus. Obstetrics and Gynecology 5: 122-126.

Walder et al., 2003. Chlamydophila abortus pelvic inflammatory disease. Emerging Infectious Diseases 9: 1642-1644.

Wang et al., 2001. Prevalence of Chlamydophila abortus infection in domesticated ruminants in Taiwan. Journal of Veterinary Medical Science 63: 1215-1220.

Wheelhouse et al., 2012. Processing of Chlamydia abortus polymorphic membrane protein $18 \mathrm{D}$ during the Chlamydial developmental cycle. PLOS ONE 7: Article \# 49190.

Wheelhouse et al., 2012. Expression patterns of five polymorphic membrane proteins during the Chlamydia abortus developmental cycle. Veterinary Microbiology 160: 525-529.

Wong et al., 1985. Acute placentitis and spontaneous abortion caused by chlamydia psittaci of sheep origin: a histological and ultrastructural study. Journal of Clinical Pathology 38: 707-711.

Yin et al., 2014. Prevalence of Chlamydia abortus in Belgian ruminants. Vlaams Diergeneeskundig Tijdschrift 4: 164-170.

Zezekalo et al., 2020. Prevalence of Chlamydia-related organisms with zoonotic potential in farms of the Poltava region. Wiadomości Lekarskie 73: 1169-1172. 